Public Health

\section{Challenges of tuberculosis}

\section{control}

$M$ ycobacterium tuberculosis infects a third of the world's population and kills 2 million people each year: there is a new infection every second. Most cases currently are located in southeast Asia, with one-third of new cases arising in this region each year (Table I, Fig. I). Rates of tuberculosis (TB) are also increasing rapidly in Africa, in parallel with the HIV/AIDS epidemic.

The continuing challenges of $\mathrm{TB}$ control can be distributed into 5 key areas: inadequate diagnostics and treatment; the need for expansion of the World Health Organization (WHO) Directly Observed Therapy, short course (DOTS) program; multidrugresistant tuberculosis (MDRTB); and HIV coinfection.

The diagnostic tools in use for TB are old and often ineffective. Sputumsmear microscopy, which was developed in I882, does not detect extrapulmonary or smear-negative $\mathrm{TB}$, and is less effective in children and people infected with HIV, whose smear results are often negative. ${ }^{1}$ Most laboratories also lack the facilities to identify MDRTB. ${ }^{2}$

Drugs currently being used to treat TB have also been on the market for many years: isoniazid was first used in I952, rifampicin in I965, and ethambutol in $1968 .{ }^{1}$ The chief problem with these drugs is the need for prolonged treatment: regimens are currently recommended for 6-9 months, and failure to adhere to long treatment courses results in resistant strains and relapse. To facilitate compliance with these onerous treatments, WHO introduced the DOTS program in I99I, which includes 5 essential components: case detection by sputum-smear microscopy, government commitment to TB control, regular supply of drugs, supervised treatment, and reports on the progress of the health system.

WHO has helped more than 180 countries implement DOTS. Despite its successes, I4 years of data have revealed the limitations of the program: globally, only $45 \%$ of the estimated cases of active TB were treated under DOTS in 2003. ${ }^{3}$ This is partly because DOTS was originally aimed at patients whose smears test positive; those with extrapulmonary or smear-negative TB (i.e., half of patients) miss inclusion in treatment programs. Although DOTS has now been expanded to include some of these people, "low-priority" patients such as those with chronic TB or MDRTB still fall outside the program's recommendations for treatment priority. ${ }^{1}$

Inconsistent or partial treatment has resulted in TB that is resistant to isoniazid and rifampicin. MDRTB accounts about $\mathrm{I} \%$ of new TB cases. ${ }^{3}$ It is a particular problem in countries of the former Soviet Union, owing to the breakdown in health system infrastructure and subsequent incomplete or inadequate treatments. Although
Table 1: Global distribution of tuberculosis by World Health Organization (WHO) region, with its estimated incidence and related mortality, 2003

\begin{tabular}{lccc}
\hline & Cases, & \multicolumn{2}{c}{ Per 100000 population } \\
\cline { 3 - 4 } WHO region & 27 & $345(42)$ & 78 \\
\hline Africa & 4 & $43(44)$ & 6 \\
\hline The Americas & 7 & $122(45)$ & 28 \\
\hline Eastern Mediterranean & 5 & $50(44)$ & 8 \\
\hline Europe & 35 & $190(45)$ & 38 \\
\hline Southeast Asia & 22 & $112(45)$ & 19 \\
\hline Western Pacific & 100 & $140(44)$ & 28 \\
\hline Global & Cases & Deaths \\
\hline Source: World Health Organization, Tuberculosis: fact sheet no. 104. Available: www.who \\
.int/mediacentre/factsheets/fs104/en/index.html (accessed 2005 Nov 8).
\end{tabular}

Source: World Health Organization, Tuberculosis: fact sheet no. 104. Available: www.who .int/mediacentre/factsheets/fs104/en/index.html (accessed 2005 Nov 8). (Wer 100000 population

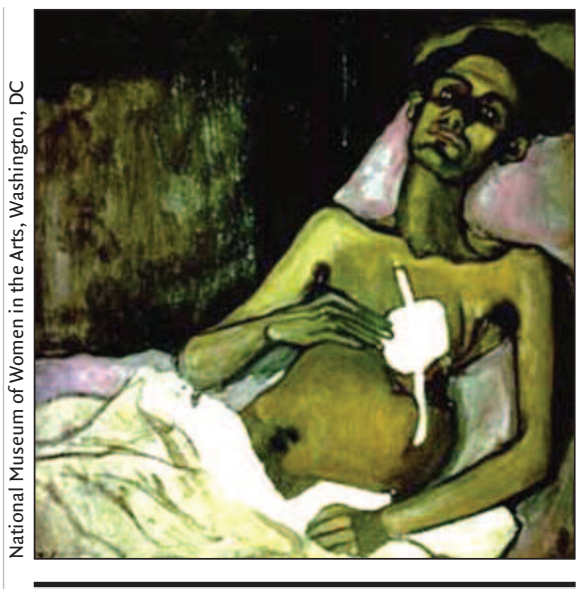

Alice Neel. T.B. Harlem, 1940. Oil on canvas.

MDRTB is generally treatable, the drugs required must be taken for up to 2 years and are considerably more expensive and toxic. ${ }^{3}$

Finally, HIV infection compounds the problems of accurate diagnosis as well as adequate treatment. TB causes more rapid deterioration of the immune systems of people with HIV or AIDS, and they are Ioo times more likely to have active TB during their lifetime than people who are HIV-negative. ${ }^{2}$ People with advanced HIV infection can have active TB that is smear-negative or without typical chest radiography features, which means that coexistent $\mathrm{TB}$ infections remain untreated.

The relapse rates associated with the use of some anti-TB regimens are increased among HIV-positive people. Concomitant use of antiretroviral drugs has clinically significant toxicity and drug interactions, and the optimum timing for antiretroviral therapy in patients with TB is still unknown. ${ }^{2,4}$ Furthermore, after starting antiretroviral drugs patients may experience an immune reconstitution syndrome that mimics many aspects of TB infection, which makes the clinical picture in coinfected patients unclear.

To address the challenges facing $\mathrm{TB}$ control, various global groups are advocating for and supporting research and development in this area (Box I). A recent new development is the wholeblood interferon $\gamma$ assay, which detects interferon in response to TB challenge, and is currently being validated in the field. ${ }^{2,4}$ Diarylquinolone is an encour- 


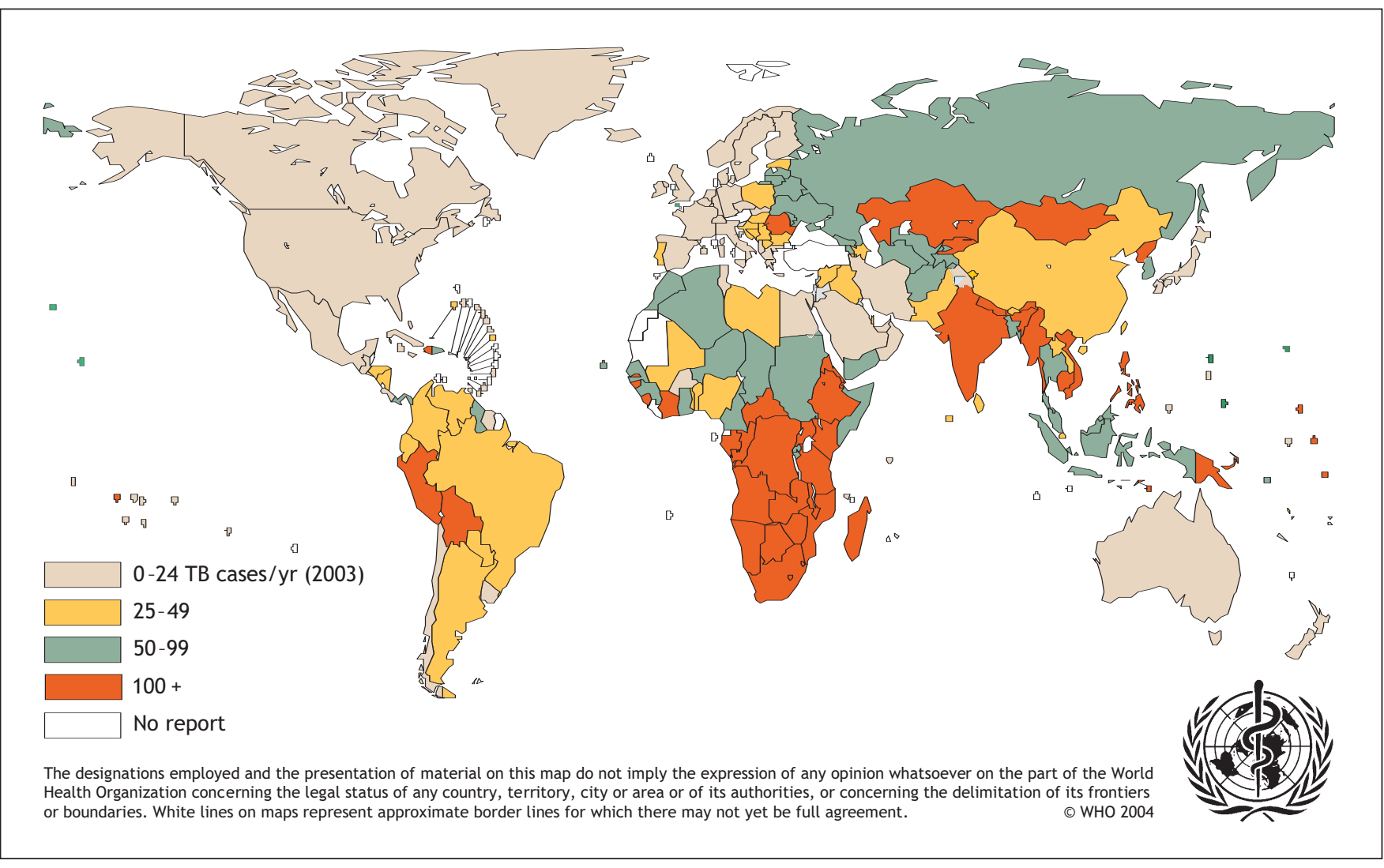

Fig. 1: Worldwide notification rates for tuberculosis for 2003. Source: the World Health Organization (WHO). ${ }^{1}$

\section{Box 1: Various initiatives addressing tuberculosis control}

- Stop TB Partnership (www.stoptb.org)

- World Health Organization Special Programme for Research and Training in Tropical Diseases (www.who.int/tdr/diseases/tb)

- The Global Fund to Fight AIDS, TB and Malaria (www.theglobalfund.org)

- International Union against Tuberculosis and Lung Disease (www.iuatld.org)

- Global Alliance for TB Drug Development (www.tballiance.org)

aging new treatment initiative that appears to be highly active against TB (including MDRTB) and requires shorter periods of treatment. Trials of vaccines are also underway, and the merits of treating latent $\mathrm{TB}$ are being debated for people who are recently infected or are at increased risk of progression to TB (e.g., people who test positive for HIV) in both developing and developed countries. ${ }^{2,4}$ The use of any new measures will need to be considered in their global context - one often plagued by poverty, over- crowding and health systems that are short on funding and trained staff.

\section{Sally Murray \\ Editorial Fellow, CMAJ}

\section{REFERENCES}

I. Médecins Sans Frontières. Running out of breath: $T B$ care in the 2Ist century. Geneva: the organization; 2005. Available: www.accessmed-msf.org /documents/tbreportseptember2004.pdf (accessed 2005 Nov 24).

2. Frothingham R, Stout JE, Dukes Hamilton C. Current issues in global tuberculosis control. Int I Infect Dis 2005;9:297-3II.

3. World Health Organization (WHO). Global tuberculosis control: surveillance, planning and financing. Geneva: WHO; 2005.

4. Blumberg HM, Leonard MK, Jasmer RM. Update on the treatment of tuberculosis and latent tuberculosis infection. JAMA 2005;293:2776-84. 